\title{
A COMPARISON OF WIND OBSERVATIONS OF THE UPPER THERMOSPHERE FROM THE DYNAMICS EXPLORER SATELLITE WITH THE PREDICTIONS OF A GLOBAL TIME-DEPENDENT MODEL
}

\author{
D. REES, T. J. FULLER-ROWELL and R. GORDON \\ Department of Physics and Astronomy, University College London, Gower Street, London WC 1E 6BT, U.K. \\ T. L. KILLEEN and P. B. HAYS \\ Space Physics Research Laboratory, University of Michigan, 2455 Hayward, Ann Arbor, MI 48109, U.S.A. \\ and \\ L. WHARTON and N, W. SPENCER \\ NASA, Goddard Space Flight Center, Greenbelt, MD 20771, U.S.A.
}

(Received in final form 30 March 1983)

\begin{abstract}
Seven polar passes of the NASA Dynamics Explorer 2(DE-2) satellite during October and early December 1981 have been used to examine the high-latitude circulation in the upper thermosphere. Vector winds along the satellite track are derived by appropriate merging of the data from the remote-sensing FabryPerot interferometer (meridional wind) and the in situ wind and temperature spectrometer (zonal wind) and are compared with the predictions of a three-dimensional, time-dependent, global model of the thermosphere. Major features of the experimental winds, such as the mean day to night circulation caused by solar u.v. and e.u.v. heating, augmented by magnetospheric processes at high latitude and the sharp boundaries and flow reversals imposed on thermospheric winds by momentum transfer (ion drag) from the magnetosphere, are qualitatively explained by a version of the global model using a semi-empirical global model of polar electric fields (Volland Model 2 or Heppner Model A) and a model of global electron density which excludes the effects of high-latitude geomagnetic processes. A second version of the global dynamic model includes a theoretical model of the high-latitude ionosphere which is self-consistent and reflects the enhancement ofionization due to magnetospheric phenomena acting in addition to solar e.u. photo-ionization, including the interactive processes which occur between ionization and high latitude ion convection and thermospheric winds. This second dynamical model shows an improved comparison with the structure and magnitude of polar cap and auroral oval winds at times of other than extremely low geomagnetic activity, when the frrst model appears a better match. An improved empirical description of the complex magnetospheric processes exciting the thermosphere in the vicinity of the dayside polar cusp and an empirical description of storm-time electric fields will be required for a quantitative explanation of the polar thermospheric winds during geomagnetic substorm events.
\end{abstract}

\section{INTRODUCTION}

The dynamics of the Earth's upper thermosphere is dominated by two major processes. The first is the heat input into the dayside hemisphere due to the absorption of solar u.v. and e.u.v. radiation within the thermosphere and the second is the mainly highlatitude excitation by a variety of energy and momentum sources of magnetospheric origin. The dynamical consequence of the first process within the middle and upper parts of the thermosphere (say above $200 \mathrm{~km}$ ) is a ubiquitous global circulation away from a pressure maximum located at approx. 14.00 L.T. and following, roughly, the solar variation in latitude throughout the year. The maximum winds (around the terminator) are about $150-250 \mathrm{~m} \mathrm{~s}^{-1}$ tending to increase over this range with solar activity. This aspect of thermospheric circulation has been considered theoretically in a number of investigations, including Kohl and King (1967), Volland and Mayr (1973), Creekmore et al. (1975), Straus et al. (1975) and more recently by Fuller-Rowell and Rees (1980) and Dickinson et al.(1981). Experimental verification of this global circulation has come from satellite orbit analyses (King-Hele el al., 1970), from high altitude rocket-borne chemical releases (Lloyd et al., 1972; Rees et al., 1972), from incoherent scatter radar data (Roble et al., 1974) and from ground-based Fabry-Perot interferometers (Hernandez and Roble, 1977).

Possible consequences of the high-latitude geomagnetic processes were pointed out by Cole (1962), and have been studied theoretically by a number of authors 
including Cole(1971), Fedder and Banks (1972), Maeda (1976) and more recently by Rees et al. (1980), FullerRowell and Rees (1981) and Dickinson et al (1982). The last two treatments have included the effects of both ion drag from the polar electric field (e.g. Heppner, 1977) and the consequent Joule heating from ionospheric currents. Experimental verification of the high latitude wind systems caused by magnetospheric processes have come from Rees (1971), DeVries(1972), Lloyd et al. (1972), Hays et al. (1979), Rees (1972), Kelley et al. (1977). Pereira et al. (1980). Hernandez and Roble (1978) and Heppner and Miller (1982). These (and other results) have described the major features of thermospheric winds at high latitude as a result of ion drag and heating from magnetospheric sources, including correlations between certain wind parameters at specific locations and the magnitude and duration of geomagnetic events. The limitations of all of the previous studies, for example to a single location, by weather or by operational time, have been dramatically relaxed with the advent of the pair of NASA Dynamics Explorer (DE) satellites. One of these satellites, DF-2, in a low eccentricity polar orbit, is instrumented to observe the vector wind distribution over an arc covering about 50 degrees in latitude around perigee. Additional data from the satellite include complementary observations of electric and magnetic fields and information on thermal and supra-thermal charged particle populations (Hofmann, 1980). In this paper, however, the discussion will concentrate on the new wind data and on its evaluation by comparison with recent theoretical global models of the thermosphere such as those of Fuller. Rowell and Rees (1980, 1981).

\section{THE SATELLITE WIND OBSERVATIONS}

Measurements of thermospheric winds by two instruments on-board the DE-2 satellite have been combined (Killeen et al., 1982,1983) to provide a vector wind distribution sampled along the satellite orbital track for regions of the orbit near perigee. The first instrument is the Fabry-Perot interferometer (FPI) (Hays et al., 1981) which remotely senses the meridional wind component by viewing the upper atmosphere airglow spectral line emissions, by limb-scanning in the plane of the satellite's orbit and observing the Doppler shift of such spectral lines. The second instrument is the wind and temperature spectrometer (WATS) (Spencer et al, 1981), which senses the cross-track or zonal wind component in situ by measuring the angle of arrival of the beam of neutral atoms entering the aperture of a mass spectrometer. Appropriate merging of the FPI and WATS data sets allowing for the geometry of limb scanning of the FPI (Killeen et al., 1982, 1983) provides a measure of the total wind vector at an altitude of about $300-350 \mathrm{~km}$ during perigee passes.

During mid October 1981, the perigee of the DE-2 satellite was at high southern latitude, with the orbit in a local time plane from 09.00 to $21.00 \mathrm{~h}$, while by early December 1981, the perigee had precessed to the northern polar region, with the satellite orbit in the dawn-dusk plane $(06.00-18.00 \mathrm{~h})$. These two periods provided successive samples of those regions of the southern and northern polar thermosphere which are directly affected by the major energy and momentum inputs from the magnetosphere. Due to temporal and spatial variations of the magnetospheric input and the Universal Time modulation of the thermosphere as the geomagnetic pole rotates about the geographic pole, no single orbit will describe the range of thermospheric phenomena which occur. However. orbits during 20/21/22 October and 3/4 December 1981 have allowed the major modulations of thermospheric winds at high latitude due both to U.T. variations and geomagnetic processes to be described in a qualitative way for both hemispheres.

\section{THE THEORETICAL MODEL}

The development of a self-consistent theoretical model of the Earth's thermosphere has been described in a series of papers (Fuller-Rowell and Rees, 1980, 1981, 1983; Fuller-Rowell et al., 1983). The model includes a full global treatment of the Navier-Stokes equations and has a range of options which introduce either theoretical or semi-empirical models of the solar energy input, the ionosphere and the major energy and momentum inputs from the magnetosphere in terms of Joule heating, ion drag and particle heating. The magnetospheric sources of energy and momentum are parameterised for different levels of geomagnetic activity. The geomagnetic input introduces a strong U.T. variation in thermospheric structure and dynamics, due to the offset of the geomagnetic poles from the geographic poles. In addition, this offset is considerably different in the North and South Hemispheres. To simulate the consequences of magnetospheric substorms, the magnetospheric energy and momentum sources can be made time dependent, following in an approximate way the behaviour of the real magnetosphere. To simulate the behaviour of the thermosphere at times of moderately disturbed geomagnetic conditions, (approx. $3<K_{p}<4$ ) (Model MD), the high latitude ionospheric electron density structure has been taken from a theoretical treatment of the polar and auroral ionosphere by Quegan et al. (1982). This option greatly improves the reality of the 
electron density distribution at high latitude, at other than extremely low levels of geomagnetic activity. To simulate more quiet geomagnetic conditions (Model Q), the semi-empirical ionospheric models of Ching and Chiu (1973) and Chiu (1975) have been used. These semi-empirical models do not reflect the auroral and polar region enhancements of electron density and other consequences of the interactions between particle precipitation, convective electric fields and induced thermospheric winds. Neither model of the polar ionosphere does, we believe, properly allow for widespread precipitation of sub-kilovolt electrons, particularly in the dayside cusp region. These particles are essential to excite the bright auroral emissions (OI 630 $\mathrm{nm}$ ) observed in the cusp region and more widely around the auroral oval even during geomagnetically quiet periods and also have important consequences for the ionosphere and the energy balance of the upper thermosphere. For the total range of geomagnetic activity $\left(1<K_{p}<4\right)$ considered here, it seems appropriate to use the polar electric field model II of Volland (1978). The momentum input of this analytical model is approximately equivalent to that of Heppner (1977) model A. For the two levels $\left(1<K_{p}<2\right.$; $3<K_{p}<4$ ) of geomagnetic input which we have chosen to simulate separately, the distinction is made by either using the semi-empirical Chiu (1975) ionosphere to simulate lower levels of geomagnetic activity, or the theoretical ionosphere model adapted from Quegan et al. (1982) which provides magnetospheric enhancements of electron density and conductivity to enhance both the ion-drag acceleration of the neutral gas and the Joule heating at high latitudes. For each level of geomagnetic activity, the model has been run with the solar illumination corresponding to (a) 16 October and (b) 21 December, approximating the real solar input appropriate to the southern and northern passes respectively. The simulations include a twoconstituent description of the thermosphere (FullerRowell and Rees, 1983) which accommodates the modification of thermospheric composition at fixed pressure levels by persistent vertical convection and horizontal advection. These composition changes are particularly important at the solstices, and at times of persistent elevated geomagnetic activity, when systematic mean meridional winds of tens of metres per second occur. No detailed description of the model used for comparison with the satellite wind data will be given here, as such descriptions can be found in Fuller-Rowell and Rees $(1980,1981,1983)$.

\section{THE DATA SET}

Table 1 summarizes the geophysical and geomagnetic conditions for the seven selected polar passes of
TABLE 1. SUMMARY OF GEOPHYSICAL AND GEOMAGNETIC CONDITONS FOR DE-2 ORBITS USED IN ANALYSIS

\begin{tabular}{|c|c|c|c|c|c|}
\hline $\begin{array}{c}\text { Orbit } \\
\text { number }\end{array}$ & Day & $\begin{array}{c}\text { Date } \\
(1981)\end{array}$ & U.T. & $K_{p}$ & $A_{p}$ \\
\hline \multicolumn{6}{|c|}{ (A) South polar passes 22-25 October 1981} \\
\hline 1181 & 295 & 22 October & 11.1 & $5_{0}$ & 72 \\
\hline 1182 & 295 & 22 October & 12.7 & $7^{+}$ & 72 \\
\hline 1200 & 296 & 23 October & 17.8 & 30 & 27 \\
\hline 1222 & 298 & 25 October & 05,4 & $5^{-}$ & 18 \\
\hline \multicolumn{6}{|c|}{ (B) North polar passes 3/4 December 1981} \\
\hline 1810 & 337 & 3 December & 19.4 & 3. & 8 \\
\hline 1813 & 337 & 3 December & 22.6 & 3 & 8 \\
\hline 1816 & 338 & 4 December & 03.4 & $3^{+}$ & 10 \\
\hline
\end{tabular}

DE-2 during 22-25 October and 3-4 December 1981. The wind data are summarized, plotted in geomagnetic coordinates, in Fig. 1. It can be seen that these orbits occur at widely different Universal Times and thus the orbits, while each crosses the geographic pole, cut the geomagnetic polar regions in a range of locations from near the dayside cusp, to the nightside auroral oval and Harang discontinuity. The October passes are close to 09.00-21.00 h Local Solar Time, while those of December are close to 06.00-18.00 L.S.T. The October orbits occurred during a period of high geomagnetic activity, with $K_{p}$ varying between 3 and $7+$. During the 3 and 4 December orbits, geomagnetic activity was less disturbed, with $K_{p}$ varying between $3-$ and $3+$ in the appropriate $3 \mathrm{~h}$ intervals. The data from the southern and northern orbits are shown in Figs. 2 and 3 respectively, where they are now plotted in geographic coordinates. In these figures, the satellite wind data (in vector form) are compared with slices, at the appropriate altitude $(320 \mathrm{~km})$ and longitude/local time, for the specific U.T. of each polar pass, taken from each of the two model simulations. Each figure has an associated polar plot of the wind field poleward of 40 degrees (geographic) taken from the model with moderate geomagnetic activity, to place the wind data in the context of the appropriate hemispheric circulation. The details of the specific models used for these comparisons are summarized in Table 2 and reflect the appropriate solar declination, a moderately high level of solar electromagnetic activity $(F 10.7 \mathrm{~cm}$ $=150$ ), and two levels of geomagnetic input corresponding to slightly disturbed ( $\left.1<K_{p}<2\right)$, and moderately disturbed $\left(3<K_{p}<4\right)$ conditions.

In each polar pass, a number of features can be readily identified

(i) There is a region of strong anti-sunward flow over the geomagnetic polar cap in which the wind speed and direction are both variable, within a given pass, and from pass to pass. 
Geomognetic totitude/LMT DE-FPI/WATS Neutrol wind vectors

From -40 to -90

South Pote

Orbits:

(a) 1181

(b) 1182

(c) 1200

(d) 1222

(a)

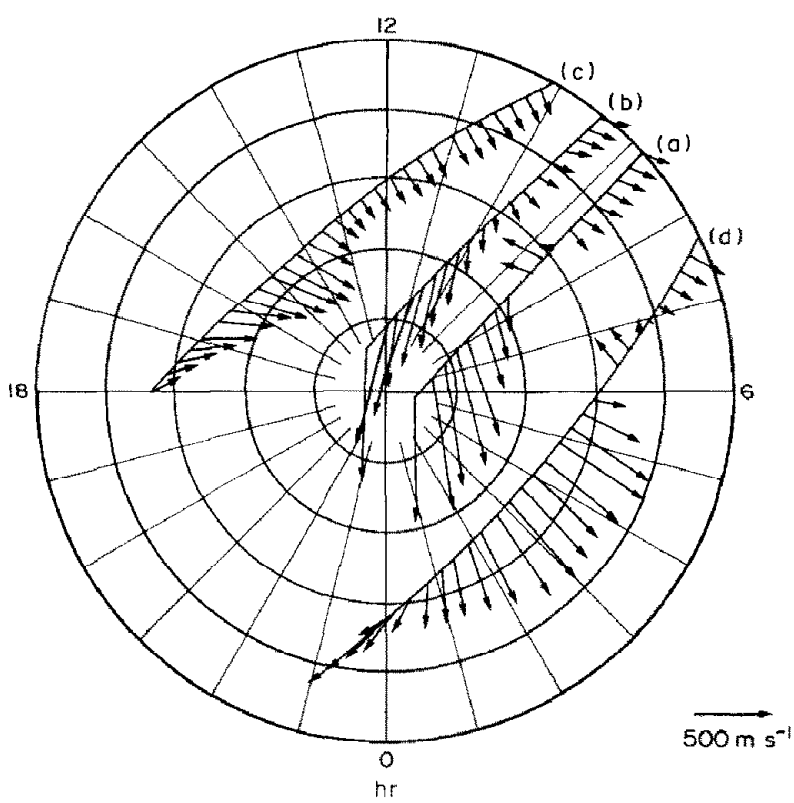

Fig. 1(a). COMPOSITE VECTOR WIND PLOT OF DATA FROM FABRY -MEROT INTERFEROMETER AND W.A.T.S. FOR FOUR SOUTHERN POLAR PERIGEE PASSES IN OCTOBER 1981.

Data are plotted in geomagnetic coordinates (latitude, local time). All orbits cross the geographic pole. (a)

Orbit 1181; (b) Orbit 1182 ; (c) Orbit 1200 and (d) Orbit 1222.

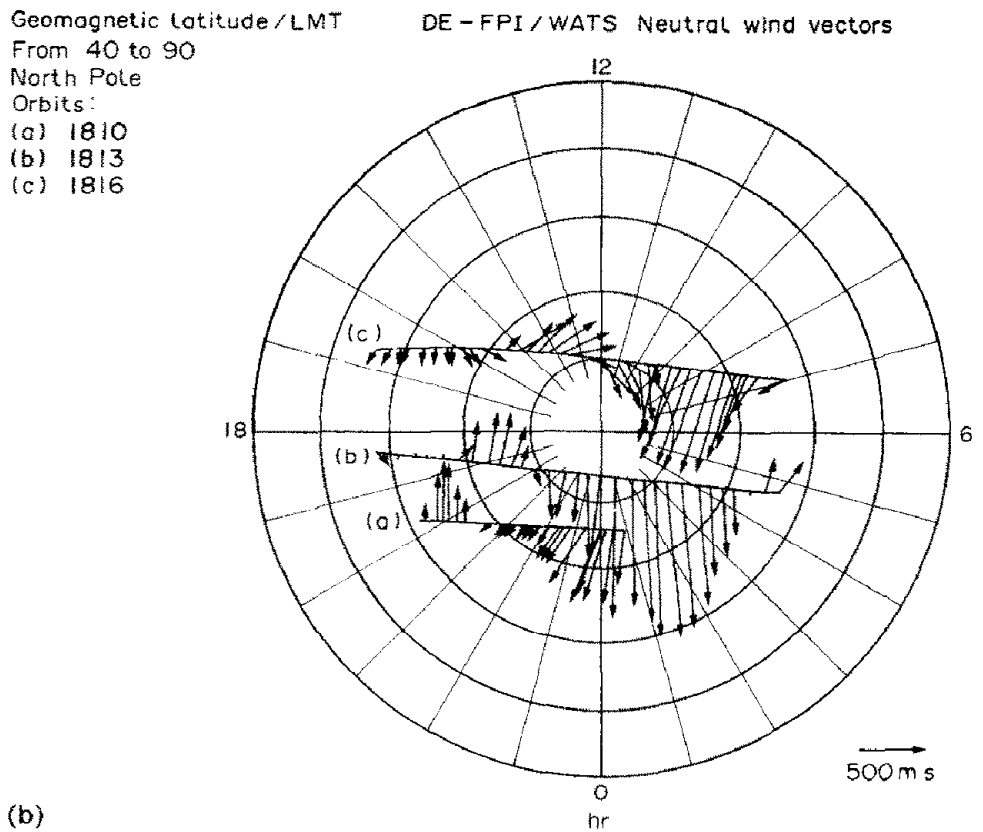

FIG. 1(b). COMPOSITE VECTOR WIND PLOT OF DATA FROM FABRY PEROT INTERFEROMETER AND W.A.T.S. FOR THREE NOR THER N POLAR PERIGEE PASSES IN DECEMBER 1981.

Data are plotted in geomagnetic coordinates (latitude, local time). All orbits cross the geographic pole. (a) Orbit 1810; (b) Orbit 1813 and (c) Orbit 1816. 

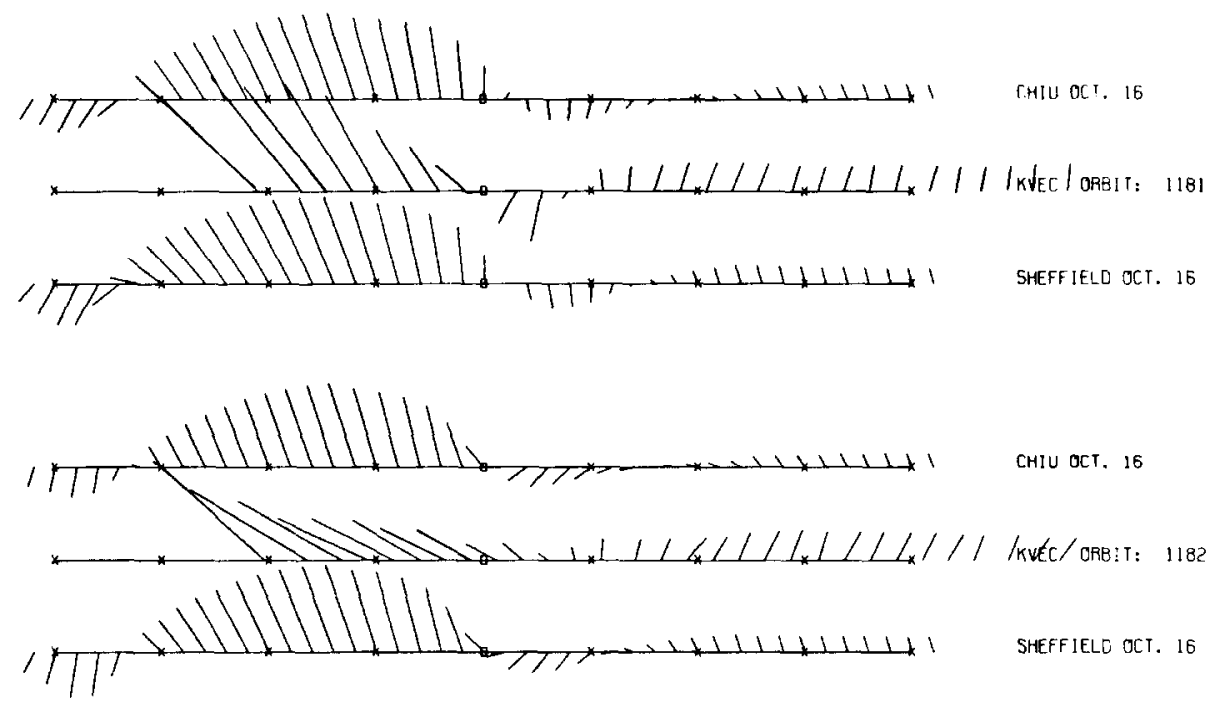

CHIU OCT, 16
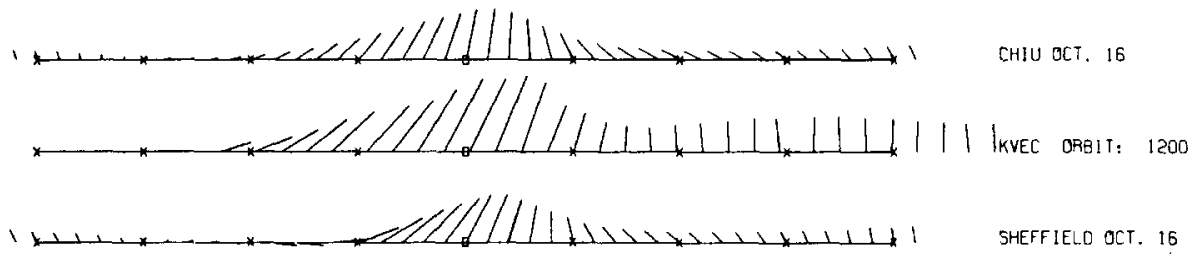
SHEFF IELD ICT. I6

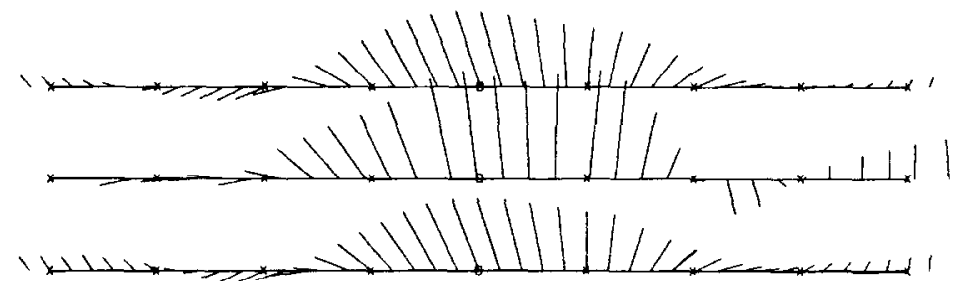

CHIU OCT, If KVEC DRE:T: I2e?

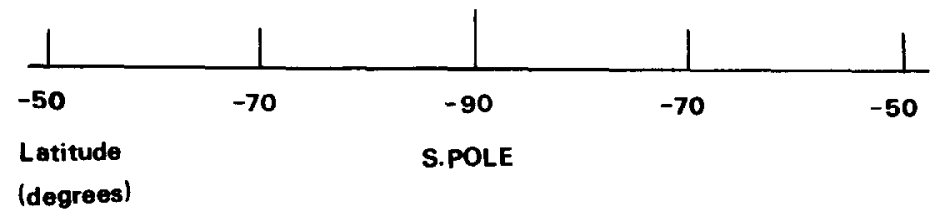

Fig. 2(a). CoMparison betWeEn Each individual SOUTHERn (OCT. 1981) POLAR Pass (Marked K VEC ORBIT NO.) AND THE CORRESPONDING POLAR SLICES FROM TWO THEORETICAL GLOBAL (THREE-DIMENSIONAL, TIMEDEPENDENT) MODEL SIMULATIONS, AT $320 \mathrm{~km}$.

Chiu-Quiet geomagnetic conditions. Sheffield-Moderately-disturbed geomagnetic conditions. Geographical latitude and local solar time are marked, referring to Fig. 1 for geomagnetic orientation and to text for detailed model explanation. Scale: $10^{\circ}$ atitude $\equiv 667 \mathrm{~m} \mathrm{~s}^{-1}$. 

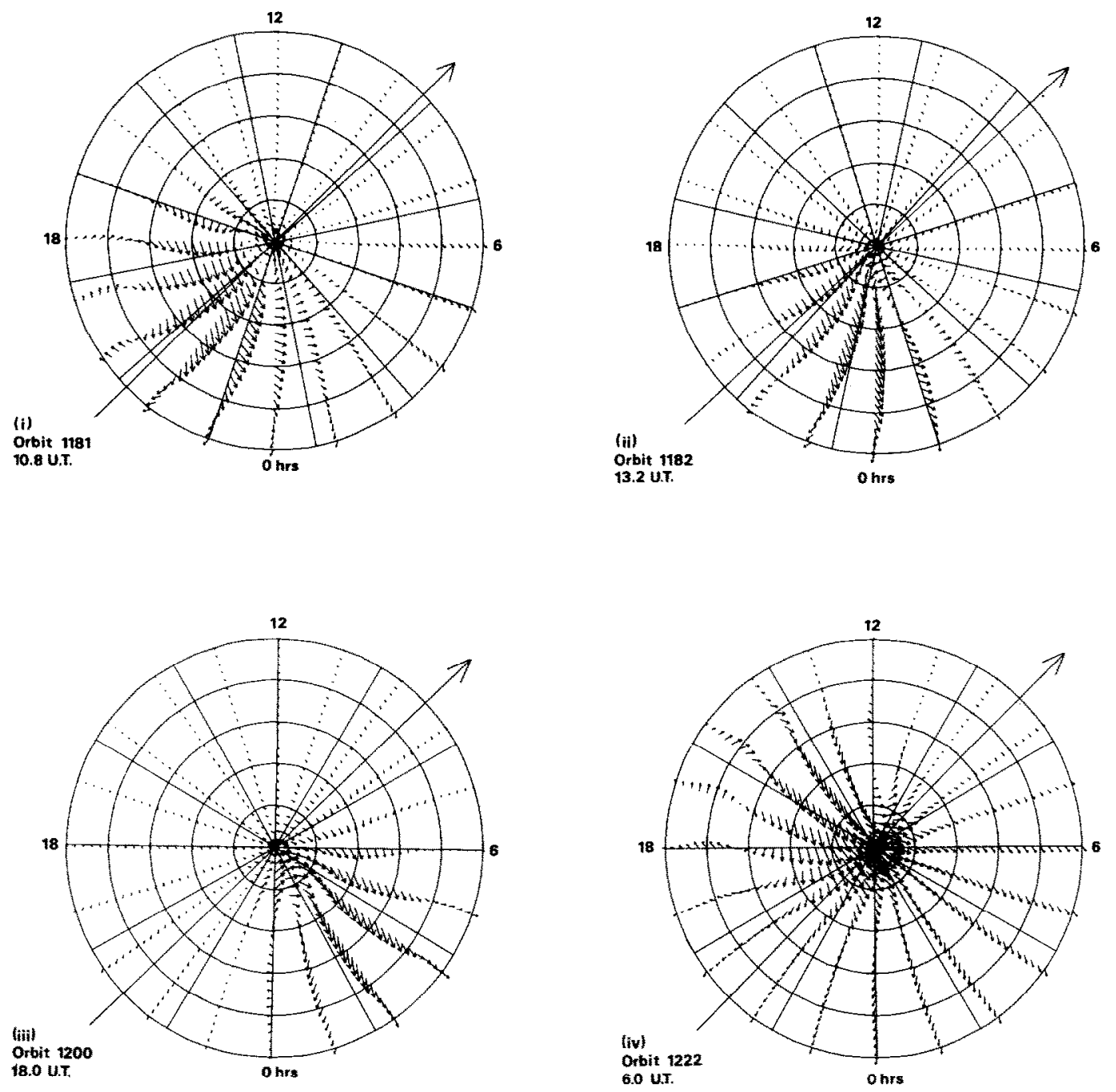

Fig. 2(b). HEMISPHERIC MODEL WIND SIMULATIONS CORRESPONDING TO THE U.T. OF EACH SOUTHERN POLAR PASS. Data shown poleward of $40^{\circ} \mathrm{S}$ latitude (geographic). (i) 10.80 U.T.; (ii) 13.20 U.T.; (iii) 18.00 U.T and (iv) 06,00 U.T.

(ii) Associated with the location of the dusk and dawn parts of the auroral oval there is a region of sunward winds (or a strong reduction of the anti-sunward wind) which corresponds to the location of the region of sunward ion flow. The major modulation of the location of this region (in a geographic frame of reference) is due to the offset of the geomagnetic pole and thus the polar ion convection pattern (Maynard 1982, private communication) from the geographic pole. A second modulation, which is not well described in this limited data set, we expect to be due to the expansion and contraction of the auroral oval, and the strengthening and weakening of the overall convection velocities in response to variations of the interactions between the solar wind and the magnetosphere.

(iii) Below the latitude of the auroral oval, the thermospheric wind again becomes anti-sunward, reverting to the pattern of thermospheric winds driven by a low-latitude solar energy source. Winds in the midlatitude region are measured (in this sample) relatively close to the terminator, and are much more consistent in magnitude and direction than those at higher latitudes.

(iv) The wind velocities at high latitude, within the two flow regimes discussed above, are highly variable. There is only a general relationship between 

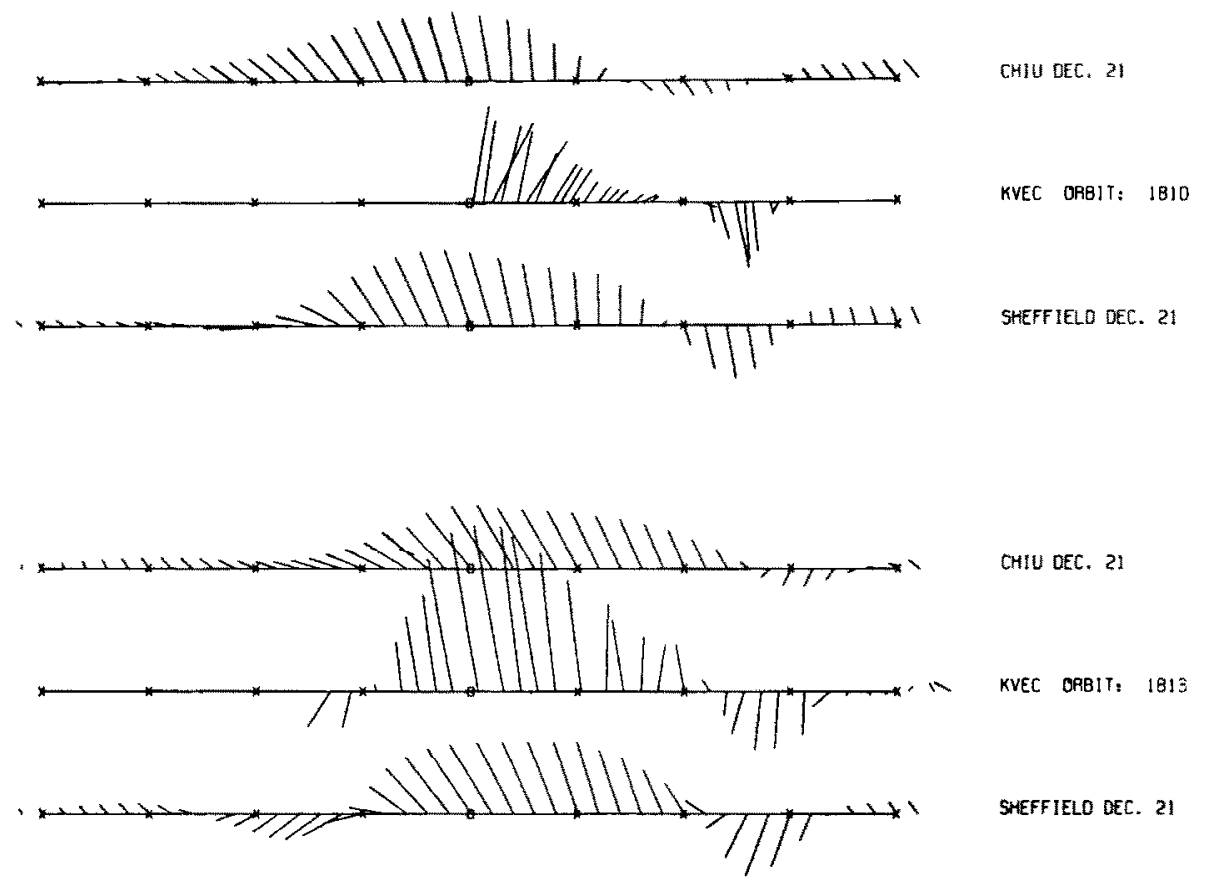

arv oEc. 21

KVEC ORBIT: $181 \mathrm{~S}$

SHEFFIELO DEC. 21

06 LST

8 LST
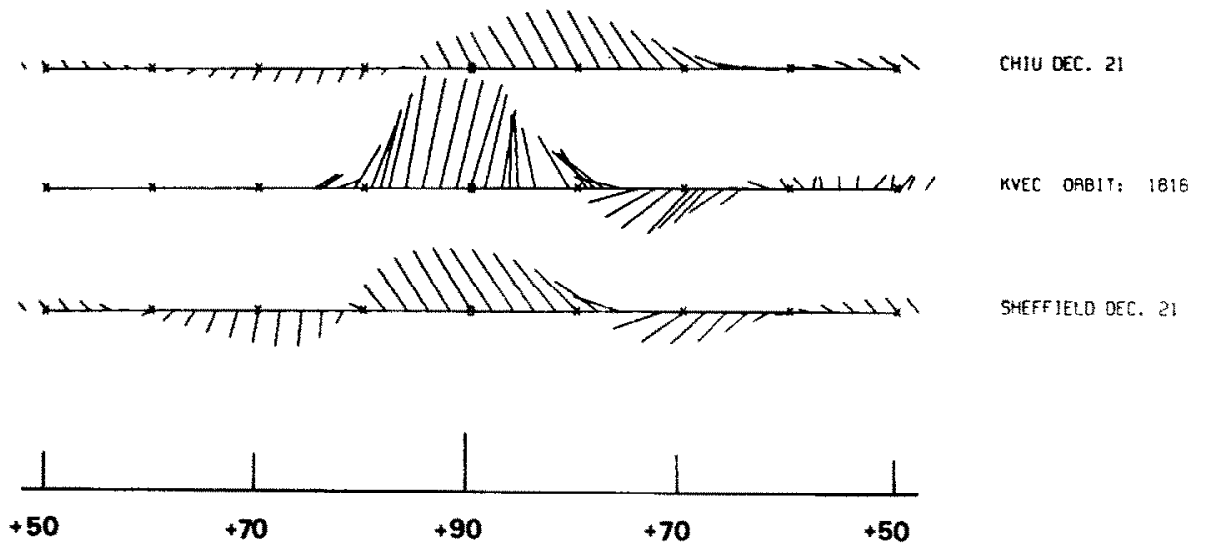

Latitude

N. POLE

(degrees)

Fig. 3(a). COMPARISON BETWEEN EACH INDIVIDUAL NOR THERN (DECEMBER 1981) POLAR PASS (MARKed KVEC ORBIT NO.) AND THE CORRESPONDING POLAR SLICES FROM TWO THEORETICAL GLOBAL (THREE-DIMENSIONAL, TIMEDEPENDENT) MODEL SMULATIONS, AT $320 \mathrm{~km}$.

Chiu-Quiet geomagnetic conditions. Sheffield-Moderately-distributed geomagnetic conditions. Geographical latitude and local solar time are marked, referring to Fig. 1 for geomagnetic orientation and to text for detailed model explanation. Scale: $10^{\circ}$ Latitude $\equiv 667 \mathrm{~m} \mathrm{~s}^{-1}$. 

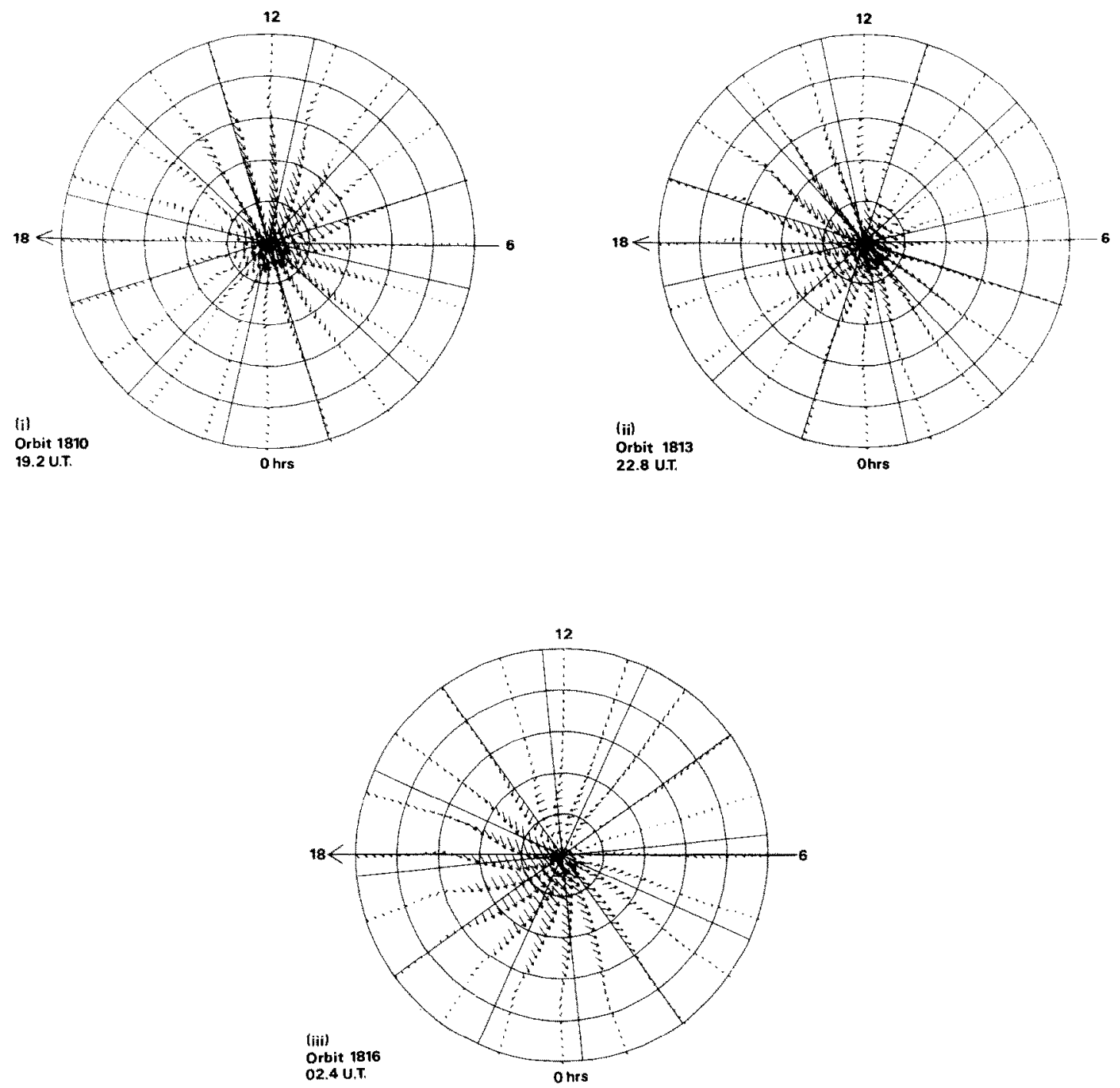

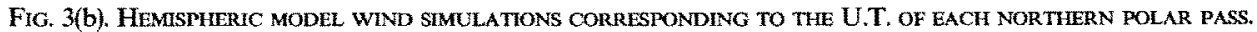
Data shown poleward of $40^{\circ} \mathrm{N}$ latitude (geographic). (i) 19.20 U.T.; (ii) 22.80 U.T. and (iii) 02.40 U.T.

geomagnetic activity and velocity. In this small sample, what geomagnetic variations are present are strongly modulated by the U.T. dependency discussed earlier. In particular, the wind velocities in specific regions can only be correlated with parameters associated with geomagnetic activity in a frame of reference which follows the changing pattern of magnetospheric convection as that is projected onto the high latitude ionosphere and thermosphere. The wind velocities in these different flow regimes, their dependence on Universal Time and response to geomagnetic events will now be considered in detail and compared with the model predictions.

\section{DISCUSSION}

Table 3 summarizes the locations of the flow boundaries which can be identified in the experimental wind data, as well as in the model results. The major phenomena are the anti-sunward flow observable below about 60 degrees geomagnetic latitude whenever data is available, the enhanced anti-sunward flow over the polar cap and the narrow regions of sunwarddirected wind in both dawn and dusk parts of the auroral oval.

In both hemispheres, all wind observations in the regions below about 60 degrees geomagnetic latitude, 
TABLE 2. SUMMARY OF ENERGY AND MOMENTUM INPUTS TO THERMOSPHERIC DYNAMICAL MODEL

A. Geomagentic input

" $Q$ " Model (Quiet $-1 \lesssim K_{p} \lesssim 2$ )

Chiu (1975) Global Ionospheric Model

Volland (1978) Model II Polar Electric Ficld

No additional high latitude particle heating/ ionization
"MD" Model (Moderate disturbance- $-3 \lesssim K_{p} \lesssim 4$ )

"Sheffield" High Latitude Ionospheric Model (adapted from Quegan et al., 1982)*

Volland (1978) Model II Polar Electric Ficld

No additional high latitude particle heating/ ionization

B. Solar u.v. +e.u.v. heating global input calculated for:

I 16 October (Solar declination -9) (October-S. Hemisphere polar passes)

II 21 December (Solar declination - 23\%)

(December - N. Hemisphere polar passes)

Solar activity $F_{10.7}=150 \times 10^{-22} \mathrm{~W} \mathrm{~m}^{-2} \mathrm{~Hz}^{-1}$

4 Global simulations-16 October (Chiu);

Disturbed model (Fig. 6)

21 December (Chiu);

16 October (Sheffield)

21 December (Sheffield)

Geomagnetic input : Expanded auroral oval and enhanced cross polar cap electric field (Maynard, 1982 ref, Rees et al.. 1983) $130 \mathrm{kV}$ cross polar cap potential

"Sheffield" High Latitude Ionospheric Model (adapted from Quegan et al., 1982)

Solar input : As for "Q" and "MD" Models (for 21 December)

*Merged with Chiu (1975) Global Ionosphere Model at low/middle latitudes.

which do not come under the direct influence of magnetospheric convection during periods of low or moderate geomagnetic activity, show a systematic antisunward flow of between 100 and about $180 \mathrm{~m} \mathrm{~s}^{-1}$ independent of U.T. or geomagnetic activity. The comparable value in the model simulation averages about $150 \mathrm{~m} \mathrm{~s}^{-1}$, which implies that the nonmagnetospheric aspects (i.e. those due to solar e.u.v. heating) of the model are in approximate agreement with the real thermosphere. However, this sample and distribution of experimental data is insufficient to warrant a more detailed analysis.

For the three northern orbits, and the four southern orbits, the comparison of each pass with the model simulations shows that the regions of the anti-sunward winds of the polar cap and the sunward winds of the auroral oval accurately correspond to the plasma convection regions as defined in the Heppner (1977) convection pattern. The particular model (A) reflects a moderate level of geomagnetic activity $\left(3<K_{p}<4\right)$, and although this model is based on a rather small sample of data from OGO 6 (in 1969), fortunately the satellite was in a near polar orbit, with a dusk/dawn configuration, similar to that of DE-2 at the time of the observations discussed here.

If ion drag were the only force acting on the neutral gas of the upper thermosphere, it might be expected (Cole, 1962) that the velocity of the neutrals would correspond closely in magnitude and direction to that of the ions (given by the local $\mathbf{E} \wedge \mathbf{B} / B^{2}$ drift). Three regions can be described by the new satellite data and by the model :

(i) In the afternoon/evening auroral oval the neutrals follow accurately the direction of the local ion drift, but have a velocity between 30 and about $60 \%$ of the average of that of the ions. Other forces, particularly inertial, Coriolis and viscosity, act to limit the neutral wind to this fraction of the local ion velocity, a fraction which we may expect to depend on the local electron density and thus on geomagnetic activity.

(ii) Over the polar cap, the neutral wind velocity shown by the D.E. data is similar to the ion drift velocity (and sometimes exceeds it). An examination of the energy and momentum terms with the UCL model indicates that high altitude heating (and $\nabla p$ forces) and inertial terms are very important in producing such high winds, which cannot be generated or maintained by ion drift acceleration alone (due to viscosity).

(iii) In the dawn/morning parts of the auroral oval, the neutral wind may or may not follow the local sunward (eastward) ion drift and generally, there is a significant equatorward component. Inertial and Coriolis (and sometimes $\nabla p$ ) forces are extremely important in this region. Conversion of sunward (eastward) ion drag momentum into an equatorward component occurs, which also limits the magnitude of any induced sunward wind component.

In the future, a more detailed analysis of the correspondence between ion convection and neutral winds will be made, using data taken simultaneously from additional DE-2 instruments - the vector electric field instrument (VEFI) (Maynard et al.. 1981), which 
D. ReEs et al.

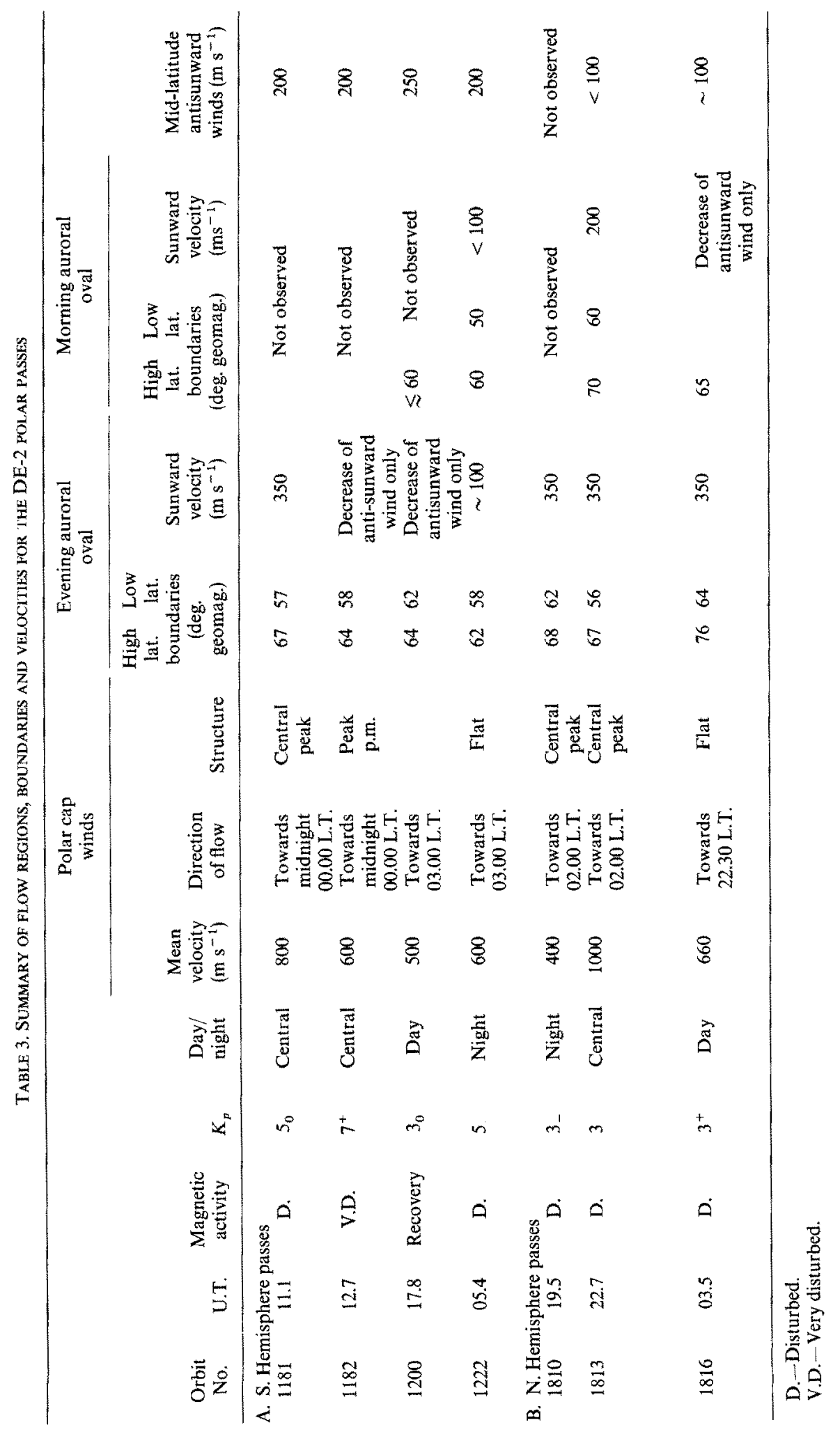


UCL 3-OIMENSIONAL TIME-DEPENOENT NEUTRAL WINO MODEL

SEPARATE GEOGRAPHIC AND GEOMAGNETIC POLES

SOUTH GEOMAGNETIC POLE : 74 DEG LAT. ; 126 DEG LONG.

SHEFFIELD ELECTRON DENSITY MODEL

VOLLAND V2 ELECTAIC FIELD MODEL

OCTOBER 16 SIMULATION

ALTITUDE (KM): 320

LOCAL TIME SECIOR : $20.4 \mathrm{HR}--\quad 8.4 \mathrm{HR}$

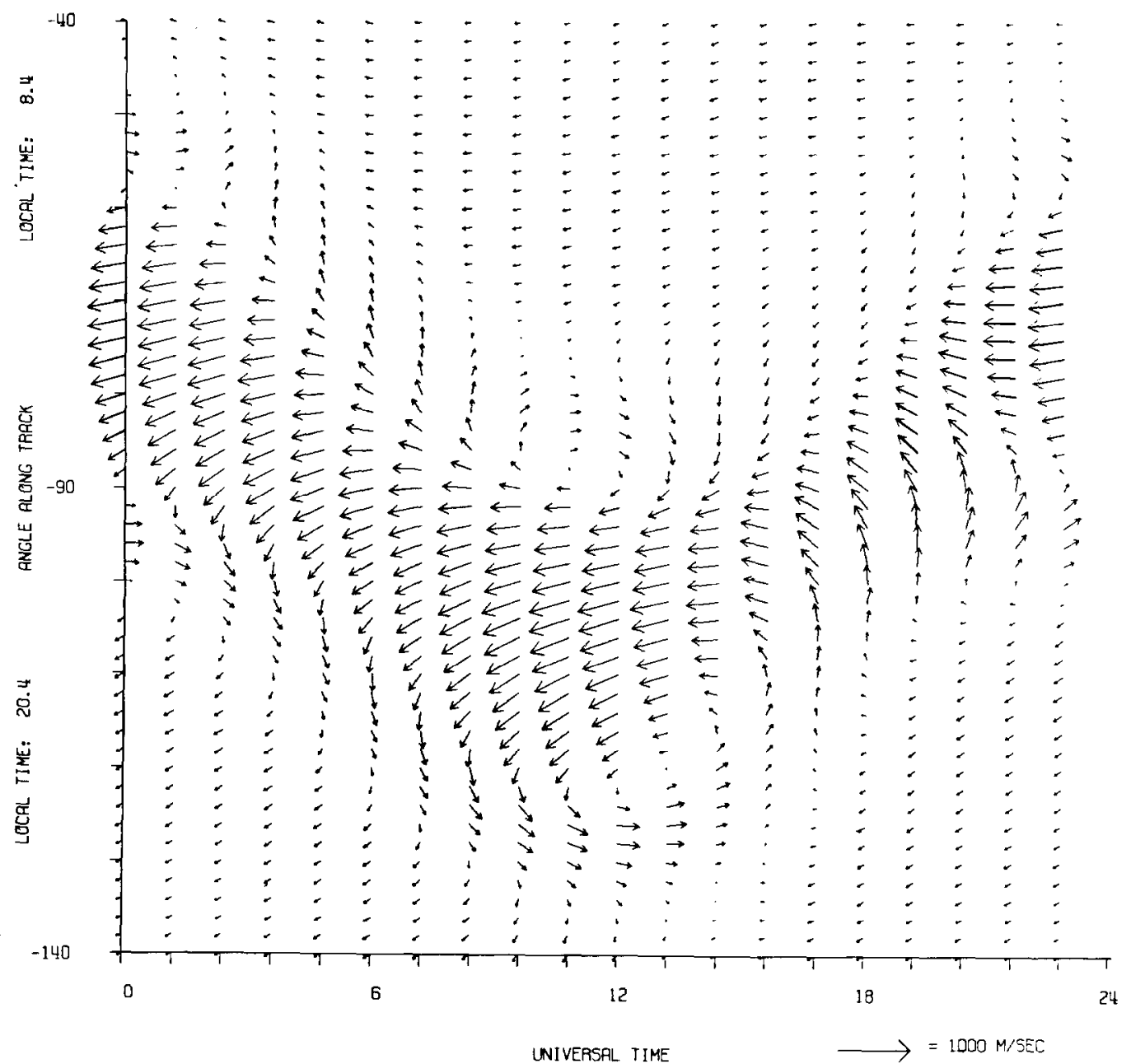

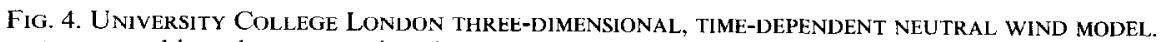
Separate geographic and geomagnetic poles. South geomagnetic pole : $74^{\circ} \mathrm{Lat}$; $126^{\circ}$ Long. Sheffield Electron Density Model plus Volland V2 Electric Field Model. 16 October simulation. Altitude $320 \mathrm{~km}$; local time sector : $20.40-08.40 \mathrm{~h}$. This presentation allows the U.T./geomagnetic dependence of vector winds from DE-2 to be compared orbit by orbit. Note this is not a flow pattern. Each slice is taken from the model at the same local time, at 1.2 (U.T.) intervals, as the Earth rotates under the plane of the satellite orbit. 
UCL 3-DIMENSIONAL TIME-DEPENDENT NEUTAPL WIND MODEL SEPARATE GEOGRPPHIC ANO GEOMAGNETIC POLES

MORTH GEOMAGNETIC POLE : 80 DEG LAT. ; 272 DEG LONG.

SHEFF IELD ELECTRON DENSITY MODEL

VOLLAND V2 ELECTRIC FIELD MODEL

DECEMBER 21 SIMULATION

ALTITUDE (KM) : $\quad 320$

LOCAL TIME SECTOR : $18.0 \mathrm{HR}-6.0 \mathrm{HR}$

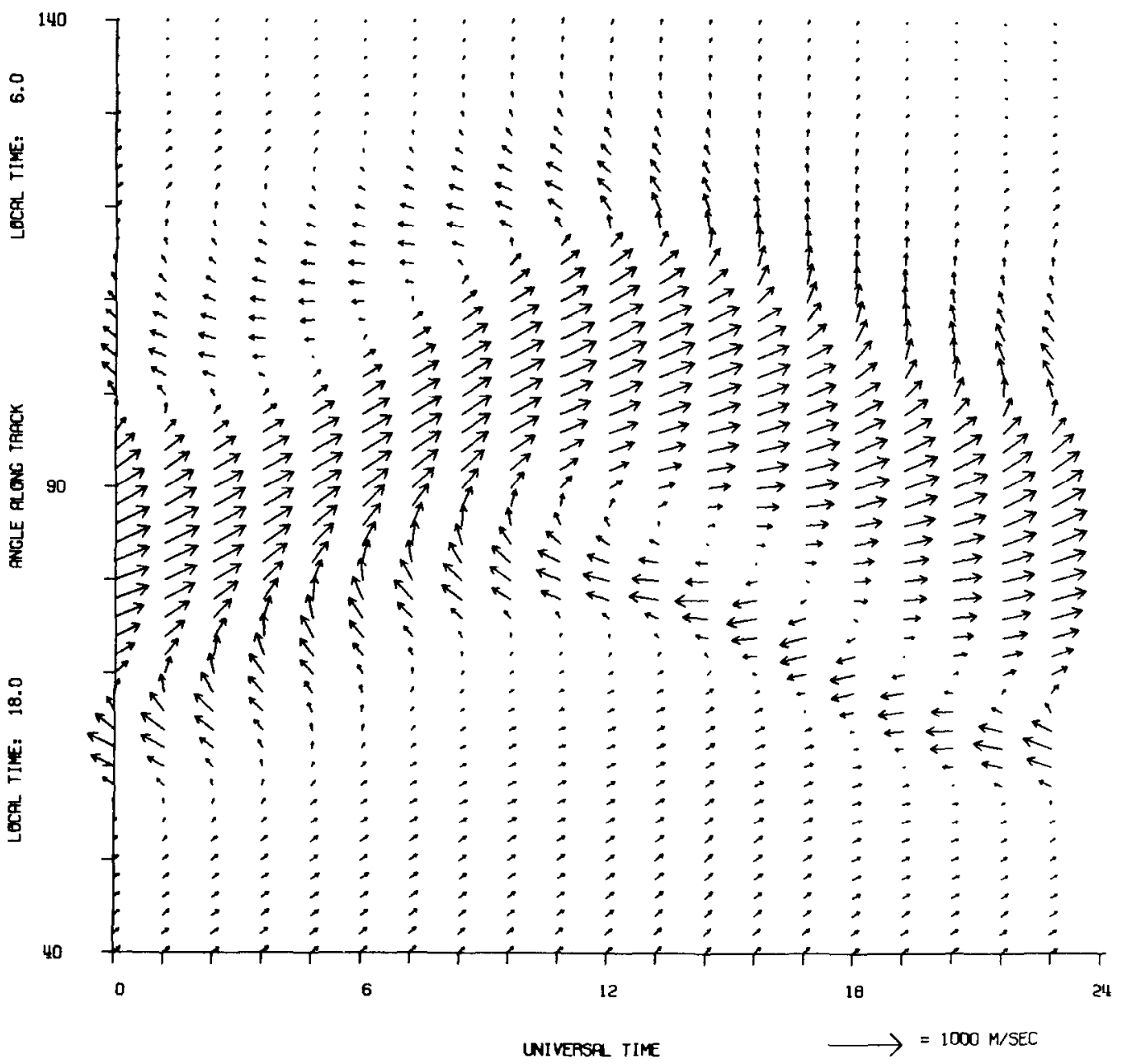

Fig. 5. University College London three-dimensional, Time-dependent neutral wind model. Separate geographic and geomagnetic poles. North geomagnetic pole : $80^{\circ}$ Lat. ; $272^{\circ}$ Long. Sheffield Electron Density Model plus Volland V2 Electric Field Model. 21 December simulation. Altitude $320 \mathrm{~km}$; local time sector : $18.00-06.00 \mathrm{~h}$. This presentation allows the U.T/geomagnetic dependence of vector winds from DE-2 to be compared orbit by orbit. Note this is not a flow pattern. Each slice is taken from the model at the same local time, at 1.2 (U.T.) intervals, as the Earth rotates under the plane of the satellite orbit. 
UCL 3-DIMENSIONAL TIME-DEPENDENT NEUTRAL WIND MODEL SEPARATE GEOGRAPHIC ANO GEOMAGNETIC POLES

NORTH GEOMAGNETIC POLE : 80 DEG LAT. ; 272 DEG LONG.

SHEFFIELD ELECTRON DENSITY MOOEL

LEF2 LARGË ELECTRIC FIELD MODEL

ALTITUDE (KM): 320

UNIVERSAL TIME : 22.8

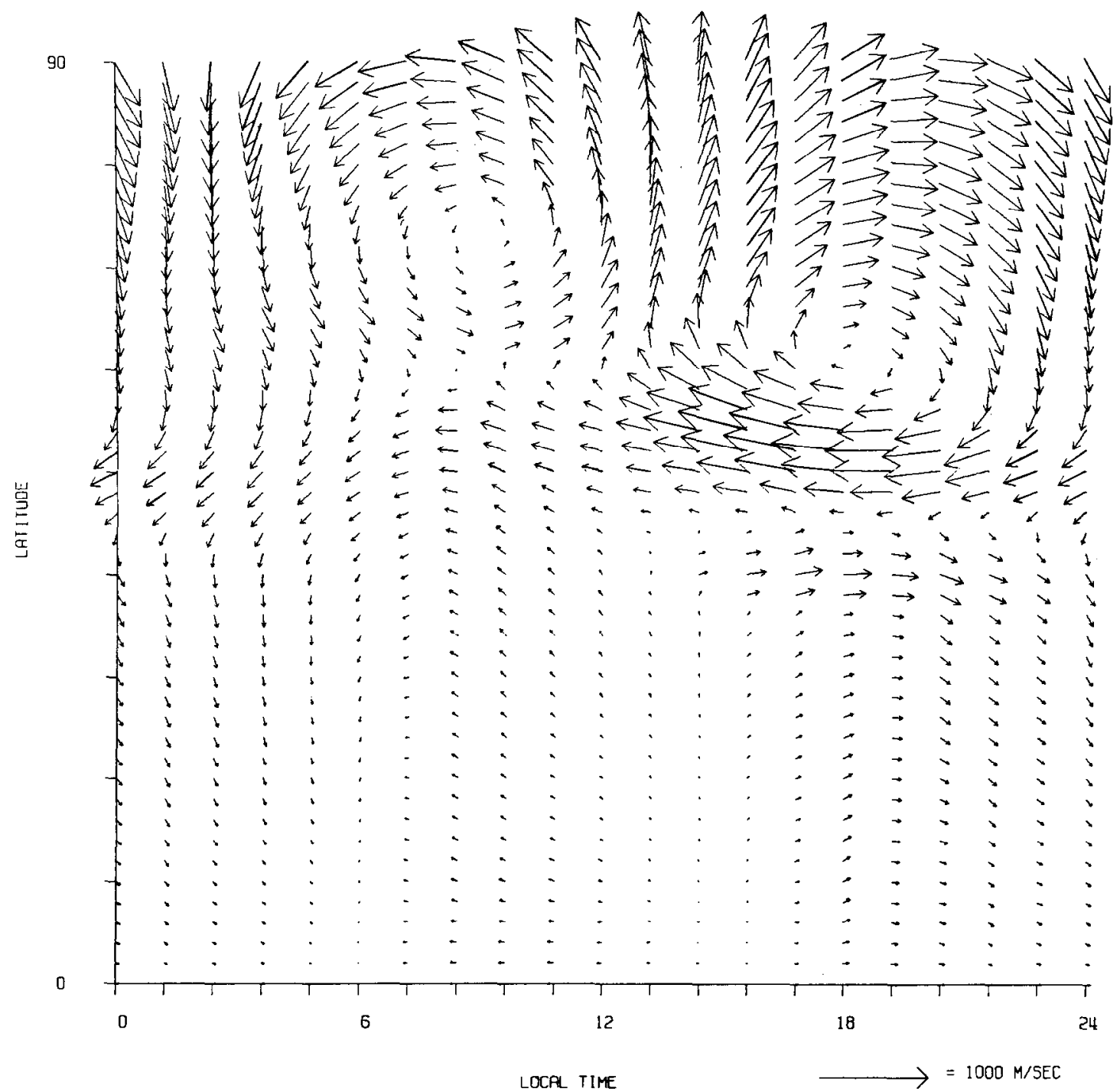

Fig. 6. Storm-time simulation, University COLlege London three-dimensional, time-DePENDENT NEUTRAL WIND MODEL.

Separate geographic and geomagnetic poles. North geomagnetic pole : $80^{\circ}$ Lat. ; $272^{\circ}$ Long. Sheffield Electron Density Model; LEF2 Large Electric Field Model; Expanded auroral oval and cross-cap potential. Altitude $320 \mathrm{~km}$; U.T. 22.80. Note: This diagram shows the actual thermospheric flow pattern at 22.80 U.T. In December 1981, the DE-2 satellite was (approx.) in the 06.00-18.00 Local Solar Time plane and thus crossing the region of peak westward winds $\left(\sim 50-60^{\circ}\right.$ geographical latitude at 22.80 U.T., over North America). 
makes in situ observations of the convective electric field and the ion drift meter (IDM), which senses the ion drift perpendicular to the satellite velocity vector (Heelis et al., 1981).

\section{Southern orbits}

The comparisons between the DE-2 data and model winds for the southern polar orbits show that the major features of experimental and model winds are in excellent agreement in respect of the locations of dusk and dawn auroral oval boundaries in the neutral flow and in the return to antisunward flow at lower latitudes. There is a very large modulation (about $45^{\circ}$ ) in the geographic location of these boundaries as a function of Universal Time. This is due to the sampling in fixed local time by the satellite and the $23^{\circ}$ co-latitude of the geomagnetic pole in the Southern Hemisphere. With the possible exception of orbit 1182 , the wind velocities observed by the satellite compare better with the model constructed to represent conditions of moderate geomagnetic activity, rather than low activity. Of particular interest is the comparison for orbit 1200 , which just skims the "throat" of the polar cusp (dayside) at a time, for this sample of orbits, of the lowest geomagnetic activity. This demonstrates very well the abrupt acceleration of the neutral gas into the polar cap by ion drag. Orbit 1182 occurred during a period of very high geomagnetic activity, when a major enhancement of ion drag acceleration of the auroral thermosphere could have been expected. There is no region of distinct and strong sunward flow in the dawn auroral oval despite the high level of activity indicated by $K_{p}$. The complex and rapid dynamical response of the thermosphere to individual substorms (Fuller-Rowell and Rees, 1981) contrasting with the $3-h$ averaging inherent in the global $K_{p}$ index is one reason for this behaviour. It is also characteristic for the sunward winds of the dawn auroral oval to be almost universally smaller in magnitude than those of the dusk auroral oval. This feature has been noted previously and discussed in some detail by Fuller-Rowell et al. (1983). Orbit 1181, which traverses across the centre of the polar cap (geomagnetic), shows an abrupt shear reversal in the wind flow at the boundary of the polar cap with the dawn oval, while the other orbits which cross the polar cap show more gradual rotational reversals. The nature of the flow transition from polar cap to auroral oval partly reflects the location of the traverse of the polar cap in the context of global thermospheric circulation and partly the detailed ion convection pattern. These features are demonstrated rather more clearly in Fig. 4 which shows the U.T. variation of the winds predicted by the moderate activity model for the south polar passes for the local time plane of the DE-2 orbit in October 1981.

\section{Northern orbits}

Orbit 1810 shows a narrow and intense region of sunward winds in the evening auroral oval, immediately following a short-lived substorm. This orbit is located toward the night-side of the auroral oval and both the experimental data and the model simulations show the gradual rotation of the wind vectors from the region of polar cap anti-sunward flow, to the sunward vectors of the auroral oval. Orbit 1813 , by comparison, is located dawn/dusk in both geomagnetic and geographic coordinates and the resulting wind vectors of DE-2 and the model show an abrupt shear-type reversal. This orbit also shows an extremely high anti-sunward polar cap wind speed, which is about a factor of $50 \%$ above the winds of even the MD model depicting moderately disturbed geomagnetic conditions. Orbit 1816 traverses close to the throat of the dayside polar cusp. Both model and DE-2 data show the rotation of neutral flow, sweeping around from the evening auroral oval and entering the polar cap through the mid-day cusp region, mapping the ion velocity pattern in this region of the high latitude ionosphere. Figure 5 shows the U.T. variation of the polar thermosphere wind for the local time plane of the DE-2 orbit in December 1981 (MD Model). The experimental data once more show that the MD model which depicts moderately disturbed geomagnetic conditions reflects thermospheric circulation at $320 \mathrm{~km}$ rather better, particularly in respect of the polar cap winds. Orbits which follow periods with geomagnetic substorms (orbit 1813), however, demonstrate a marked tendency for the observed polar cap winds to be higher than shown in the MD model simulation. In Fig. 6 a simulation corresponding to orbit 1813 is shown where the polar electric field pattern has been considerably enhanced, in addition to ionospheric enhancements, as might correspond to a high level of geomagnetic activity $\left(5<K_{p}<7\right)$. In this simulation, the auroral oval winds are higher than the experimental observations, but the polar cap winds still do not reach the magnitude of those seen during orbit 1813.

\section{SUMMARY}

The MD neutral wind models which include a theoretical enhancement of electron density within the auroral oval due to interacting magnetospheric/ ionospheric/thermospheric processes consistently show sharper wind structures than the $Q$ models (based on the Chiu (1975) ionospheric model). They also show 
higher wind velocities in the auroral oval, both features which are shown by the DE-2 wind data. Apparently, even during periods of relatively quiet geomagnetic conditions (such as orbits 1810 and 1816), a modest enhancement of the ion and electron density in the middle and upper " $F$ " region exists, above the level of ionization due to solar photo-ionization and represented by the Chiu model. The small recombination rates of the upper " $F$ " region, and the particular paths traced out by flux tubes under the influence of magnetospheric convection (Quegan et al., 1982), allow such enhancement even in the absence of discrete substorms, due to a continuous low level of magnetospheric particle precipitation. Substorminduced enhancement of electron density in the upper " $F$ " region (above $300 \mathrm{~km}$ ) will only decay slowly for the same reason (Roble and Rees, 1977). The comparison between the two simulations and the experimental data stress the correlation between winds and the ion convection pattern in the geomagnetic polar regions. The comparison also demonstrates that the auroral enhancement of ionization is a crucial factor in determining not only the wind magnitudes which are produced by ion drag, but also the characteristic shapes of the signatures of the high latitude wind disturbances as sampled by a polar-orbiting satellite. For the orbits selected here, a single pattern of the magnetospheric electric field (Volland Model 2 or Hepper Model A) has been adequate to explain the major wind features. This is by no means always the case. During very disturbed periods, as the size of the auroral oval expands and the ion convection intensifies, the wind patterns and magnitudes are seen to accommodate to the increased diameter of the auroral oval in addition to the increasing momentum input. This effect is illustrated in the storm simulation shown in Fig. 6 and will be discussed in detail in future papers. Using the data from the seven orbits discussed here it is not possible to distinguish clearly between the effects of the high latitude momentum input to the thermosphere and those due to the associated heating processes (Joule heating and particle heating). In future papers it will be possible to extend the scope of the discussion to include such effects, using data from a wider range of orbits covering a greater variety of local times. In particular, the major effects of high latitude heating become apparent in the local time region from midnight to about 06.00 , and extend to relatively low latitudes.

\section{REFERENCES}

Ching, B. K. and Chiu, Y.T.(1973) A phenomenological model of global ionospheric electron densities in the $E_{1}, F_{1}$ and $F_{2}$ regions. J. atmos. terr. Phys. 35, 1615.
Chiu, Y. T. (1975) An improved phenomenological model of ionospheric density. J. atmos. terr. Phys. 37, 1563.

Cole, K. D. (1962) Joule heating of the upper atmosphere. Australian J. Phys. 15, 223.

Cole, K. D. (1971) Electrodynamic heating and movement of the thermosphere, Planet. Space Sci. 19, 59.

Creekmore, S. P., Straus, J. M., Harris, R. M., Ching, B. K. and Chiu, Y. T. (1975) A global model of thermospheric dynamics. I. Wind and density fields derived from a phenomenological temperature. J. atmos. terr. Phys. 37. 491.

De Vries, L. L. (1972) Structure and motion of the thermosphere shown by density data from the low-G accelerometer calibration system (LOGACS). Space Res. XII, 867.

Dickinson, R. E., Ridley, E. C. and Roble, R. G.(1981) A threedimensional general circulation model of the thermosphere. J. geophys. Res. 86, 1499.

Dickinson, R. E., Ridley, E. C. and Roble, R. G. (1982) The global circulation and temperature structure of the thermosphere with high-latitude plasma convection. $J$. geophys. Res. 87, 1599.

Fedder, J. A. and Banks, P. M. (1972) Convection electric fields and polar thermospheric winds. J. geophys. Res. 77, 2328.

Fuller-Rowell, T. J. and Rees. D. (1980) A three-dimensional, time-dependent, global model of the themiosphere. $J$. atmos. Sci. 37, 2545.

Fuller-Rowell, T. J. and Rees, D. (1981) A three-dimensional, time-dependent, simulation of the global dynamical response of the thermosphere to a geomagnetic substorm. $J$. atmos. terr. Phys, 43, 701 .

Fuller-Rowell, T. J. and Rees, D. (1983) A three-dimensional, time-dependent model of the thermosphere for a twoconstituent gas. 1. Comparison with semi-empirical models for low geomagnetic activity. Planet. Space Sci. (submitted).

Fuller-Rowell, T. J., Quegan, S., Rees, D. and Moffett, R. J. (1983) The effect of realistic conductivities on high latitude neutral circulation. Geophys. Res. Lett. (to be submitted).

Hays, P. B., Meriwether, J. W. and Roble, R. G. (1979) Nighttime thermospheric winds at high latitudes. J. geophys. Res. 84, 1905.

Hays, P. B., Killeen, T. L. and Kennedy, B. C. (1981) The Fabry-Perot interferometer on Dynamics Explorer. Space Sci. Inst. 5, 395.

Heelis, R. A.. Hanson, W. B.. Lippincott, C. R., Zuccaro, D. R., Harmon, L. H.. Holt. B. J., Doherty, J. E. and Power, R. A. (1981) The ion drift meter for Dynamics Explorer-B. Space Sci. Inst. 5, 511.

Heppner, J. P.(1977) Empirical models of high latitude electric fields. J. geophys. Res. 82, 1115.

Heppner, J. P. and Miller, M. L. (1982) Thermospheric winds at high latitudes from chemical release observations. $J$. geophys. Res. 87, 1633.

Hernandez, G. and Roble, R. G.(1977) Direct measurements of night-time thermospheric winds and temperature. 3. Monthly variations during solar minimum. J.geophys. Res. $\mathbf{8 2}, 5505$

Hernandez, G. and Roble, R. G. (1978) Observations of largescale thermospheric waves during geomagnetic substorms. J. geophys. Res. 83, 5531 .

Hoffman, R. A. (1980) Dynamics Explorer Program. EOS 61. 689.

Kelley, M. C., Jørgensen, T. S. and Mikkelsen, I. S. (1977) Thermospheric wind measurements in the polar region. $J$. atmos. terr. Phys. 39, 211. 
Killeen, T. L., Hays, P. B., Spencer, N. W. and Wharton, L. E. (1982) Neutral winds in the polar thermosphere as measured from Dynamics Explorer, Geophys. Res. Lett. 9 , 957.

Killeen, T. L., Hays, P. B., Spencer, N. W. and Wharton, L. E. (1983) Neutral winds in the polar thermosphere as measured from Dynamics Explorer. Advances in Spacc Research II. (Proc. of 1982 COSPAR at Ottawa) (in press).

King-Hele, D. J., Scott, D. W. and Walker, D. M. C. (1970) Upper atmosphere rotational speed and its variation with height. Planet. Space Sci. 18, 1433.

Kohl, H. and King, J. W. (1967) Atmospheric winds between 100 and $700 \mathrm{~km}$ and their effects on the ionosphere. J. atmos. terr. Phys. 29, 1045.

Lloyd, K. H., Low, C. H., McAvaney, B. J., Rees, D. and Roper, R. G. (1972) Thermospheric observations combining chemical seeding and ground-based techniques. I. Winds, turbulence and the parameters of the neutral atmosphere. Planet. Space Sci. 20, 761.

Maeda, H. (1976) Neutral winds and ion drifts in the polar ionosphere caused by convection electric fields. $-1 . J$. atmos. terr. Phys. 38, 197.

Maynard, N. C., Bielecki, E. A. and Burdick, H. F. (1981) Instrumentation for vector electric field measurements from Dynamics Explorer-B. Space Sci. Instr. 5, 523.

Pereira, E., Kelley, M. C., Rees, D., Mikkelsen, I. S., Jørgensen, T. S. and Fuller-Rowell, T. J. (1980) Observations of neutral wind profiles between 115 - and $175-\mathrm{km}$ altitude in the dayside auroral oval. J. geophys. Res. 85, 2935.

Quegan, S., Bailey, G. J., Moffett, R. J., Heelis, R. A., FullerRowell, T. J., Rees, D. and Spiro, R. W. (1982) A theoretical study of the distribution of ionization in the high latitude ionosphere and the plasmasphere: first results on the midlatitude trough and the light-ion trough. J. atmos. terr. Phys. 44, 619.
Rees, D. (1971) Ionospheric winds in the auroral zone. J. Br. Interplanet. Soc. 24, 233.

Rees, D. (1972) Winds and temperatures in the auroral zone and their relations to geomagnetic activity. Phil. Trans. $R$. Soc. Lond. A 271, 563.

Rees, D., Roper, R. G., Lloyd, K. H. and Low, C. H. (1972) Determination of the structure of the atmosphere between 90 and 250 kilometres using contaminant releases. I. Woomera, May 1968. Phil. Trans. R. Soc. Lond. A 271, 631.

Rees, D., Fuller-Rowell, T. J. and Smith R. W. (1980) Measurements of high latitude thermospheric winds by rocket and ground-based techniques and their interpretation using a three-dimensional, time-dependent dynamical model. Planet. Space. Sci. 28, 919.

Roble, R. G., Emery, B. A., Salah, J. E. and Hays, P. B. (1974) Diurnal variation of the neutral thermospheric winds determined from incoherent scatter radar data. J. geophys. Res. 79, 2868.

Roble, R. G. and Rees, M. H.(1977) Time-dependent studies of the aurora : Effects of particle precipitation on the dynamic morphology of ionspheric and atmospheric profiles. Planet. Space. Sci. 25, 991.

Spencer, N. W., Wharton, L. E., Niemann, H. B., Hedin, A. E., Carignan, G. R. and Maurer, J. C. (1981) The Dynamics Explorer wind and temperature spectrometer. Space. Sci. Inst. 5, 417.

Straus, J. M., Creekmore, S. P., Harris, R. M., Ching, B. K. and Chiu, Y. T. (1975) A global model of thermospheric dynamics. II. Wind, density and temperature fields generated by FIVV heating. I. atmos. terr. Phys. 37, 1245.

Volland, H. and Mayr,H.G.(1973) A numerical study of threedimensional diurnal variations within the thermosphere. Ann. Geophys. 29, 61 .

Volland, H. (1978) A model of the magnetospheric electric convection field. J. geophys. Res. 83, 2695. 